Jpn. J. Med. Mycol.

Vol. 30, 187-190, 1989

ISSN $0583-0516$

原著

\title{
Effect of Chemical Modification on the Hemolytic Activity of Asp-Hemolysin from Aspergillus fumigatus
}

\author{
Katsushi Yokota, Syunya Ichinowatari and Keiichi Ebina \\ The First Department of Hygienic Chemistry, Tohoku College of Pharmacy, \\ 4-4-1 Komatsushima Sendai, Miyagi 981
}

[Received for Publication: February 9, 1989]

\begin{abstract}
Amino acid residues involved in the hemolytic active site of Asp-hemolysin from Aspergillus fumigatus were analyzed. The hemolytic activity of the toxin for human erythrocytes was found to be inactivated by the following modification procedures: arginine residue with 1,2cyclohexadione (CHD), arginine and tyrosine residues with 2,3-butanedione (BDO), and reductive methylation (RM) of lysine residue with formalin. The results indicate that arginine and/or lysine residues in toxin play an important role as a binding site to erythrocyte ghost membranes. Based on these results, a possibility of amino acid residues involved in the binding and the hemolytic active sites of Asp-hemolysin molecule was therefore studied.
\end{abstract}

Key wored: Aspergillus fumigatus, Asp-hemolysin, hemolytic active site, binding site, chemical modification

Asp-hemolysin, a thermolabile protein toxin produced by Aspergillus fumigatus FreseniusMuramatsu strain, has been purified and the biological properties of the toxin have been reported $^{1,2)}$. This toxin has been shown to promote the establishment and development of an experimental Aspergillus infection in mice ${ }^{3)}$. We have further observed multiple biological functions of Asp-hemolysin as a virulence factor ${ }^{4}$. Amino acid residues in the hemolytic active site of Asphemolysin have been studied by photochemical oxidation $^{5}$. On the other hand, chemical modification of Asp-hemolysin with 5,5'-dithiobis (2-nitrobenzoic acid) (DTNB), 2-2'-dithiodipyridine (2PDS), 4-4'-dithiodipyridine (4-PDS), $\beta$-naphthoquinone-4-sulfonic acid (NQS), 2,4,6-trinitro benzene sulfonic acid (TNBS) or glyoxal also suggested that one cysteine residue and/or or more arginine residue are involved in the hemolytic activity $^{6}$. We have reported that arginine residues

\footnotetext{
別冊請求先：横田 勝司

干981 仙台市小松島 4-4-1

東北薬科大学第一衛生化学教室
}

in Asp-hemolysin play an important role as a binding site on human erythrocyte ghosts ${ }^{7}$. We recently reported that the toxin produces morphological changes in human erythrocyte membranes in which patches- or cap-forms are observed by scanning electron microscopy ${ }^{8}$. A similar result was also found in chicken erythrocyte membranes ${ }^{9}$.

In this study, we will extend our investigations on binding site and hemolytic active site in the Asp-hemolysin molecule. To investigate the presence of the two active sites, chemical modifications with 1,2-cyclohexadione (CHD) and 2,3butanedione (BDO), and the reductive methylation $(\mathrm{RM})$ of the toxin were carried out.

\section{Materials and Methods}

Materials: Aspergillus fumigatus was incubated under stationary condition at $30^{\circ} \mathrm{C}$ for 14 days in Sabouraud broth medium containing $0.5 \%$ heart infusion broth (Difco Lab., Detroit, Mich., U.S.A.). Highly purified Asp-hemolysin was prepared by the method using various column chromatographies described previously ${ }^{2}$, and was proved to 
be homogeneous by disc electrophoretic analysis and immunodiffusion plate test. CHD and BDO were purchased from Nakarai Chemicals Ltd., Kyoto. All other chemicals were commercial products of reagent grade.

Modification of the toxin: To determine the hemolytic active site and binding site of Asphemolysin, chemical modifications with CHD, BDO and RM were made under various conditions. The CHD modification of Asp-hemolysin was done according to the method of Patthy and Smith ${ }^{10,12)}$. Various amounts of CHD were dissolved in $0.5 \mathrm{ml}$ each of $0.2 \mathrm{M}$ borate buffer $(\mathrm{pH}$ 8.1 ), and added to the toxin ( $1 \mathrm{mg})$. The mixture solution was incubated for $1 \mathrm{hr}$ at $37^{\circ} \mathrm{C}$. Chemical modiffication of the toxin $(1 \mathrm{mg})$ with BDO was carried out by incubating the toxin with various concentrations of BDO in $0.2 \mathrm{M}$ borate buffer $(\mathrm{pH}$ 8.1) for $2 \mathrm{hr}$ at $25^{\circ} \mathrm{C}^{11,13)}$. RM modification of the toxin was achieved by the method of Weisgraber et al. ${ }^{14)}$. The methylation of the toxin $(1 \mathrm{mg})$ was performed in $0.3 \mathrm{M}$ borate buffer $(\mathrm{pH} 9.0)$ at $0^{\circ} \mathrm{C}$ by addition of sodium borohydride (1 mg) followed by additions of 1 to $7 \mu \mathrm{l}$ of $37 \%$ formaldehyde solution (formalin) five times.

Assay of remaining hemolytic activity: After treatment with $\mathrm{CHD}, \mathrm{BDO}$ and RM, excess chemical reagent in each modification was removed by gel filtration on a Sephadex G-25 column, and then the remaining hemolytic activity was measured according to the method reported in our previous paper ${ }^{11}$. The remaining hemolytic activities were expressed as percentages of that of the sample before preincubation (zero time; 100\%).

Determination of binding rate: The rate of binding of the chemically modified Asp-hemolysin to human erythrocyte ghost membranes was determined according to the method of Mancini et al. ${ }^{15)}$. The mixture solution was incubated for $1 \mathrm{hr}$ at $21^{\circ} \mathrm{C}$, and centrifuged for $20 \mathrm{~min}$ at $15,000 \mathrm{rpm}$. The supernatant fluid was isolated and then the binding rate in supernatant fluid was determined by the single radial immunodiffusion technique using anti-Asp-hemolysin serum. The binding rate was estimated by comparing the curves of the diameters of halos produced in the presence of various amounts of the toxin with the standard curve on semilogarithmic paper. When the diameter of halo was $0 \mathrm{~mm}$, the binding rate was considered to be $100 \%$, and when halos had the same diameter as that of toxin alone, the binding rate was $0 \%$.

Amino acid analysis: Amino acid analysis was performed with a Hitachi Model 835-50 amino acid analyzer on samples hydrolyzed with $6 \mathrm{~N} \mathrm{HCl}$ in a sealed tube for 24 and $48 \mathrm{hr}$ at $105^{\circ} \mathrm{C}$.

\section{Results and Discussion}

\section{Hemolytic activity of modified toxin}

As shown in Fig. 1, hemolytic activity of Asphemolysin was rapidly inactivated by $\mathrm{CHD}$ - and BDO-modification. Both CHD and BDO have been widely used as a reagent for specific chemical modificaiton of arginine residue in proteins ${ }^{10,11)}$, and RM selectively modified lysine residue of lipoproteins ${ }^{14}$. In CHD and BDO-modifications, the inactivation was achieved after the modificaiton of 4 to 6 arginine residues per mole of the toxin. The hemolytic activity was inactivated completely by RM of 4 to 5 lysine residues in an Asp-hemolysin molecule. Considering the results of RM together with the complete inactivation of the toxin by $\mathrm{CDH}$ and BDO-modification, it is possible that lysine and arginine residures may contribute to in the hemolytic function of the toxin.

\section{Binding ability of modified toxin}

Figure 2 shows the binding rate of chemically modified Asp-hemolysin to human erythrocyte ghost membranes compared with that of the native toxin. In the control, to which chemical reagents were not added, binding of the toxin to the ghosts was observed, at an approximate rate of $100 \%$. Both RM and CHD-modification strongly inhibited the binding. Similar results have been observed previously ${ }^{7)}$ in the binding function of the toxin modified with glyoxal, TNBS or DTNB. However, a significant decrease in the antigenic reactivity was observed when the toxin was 


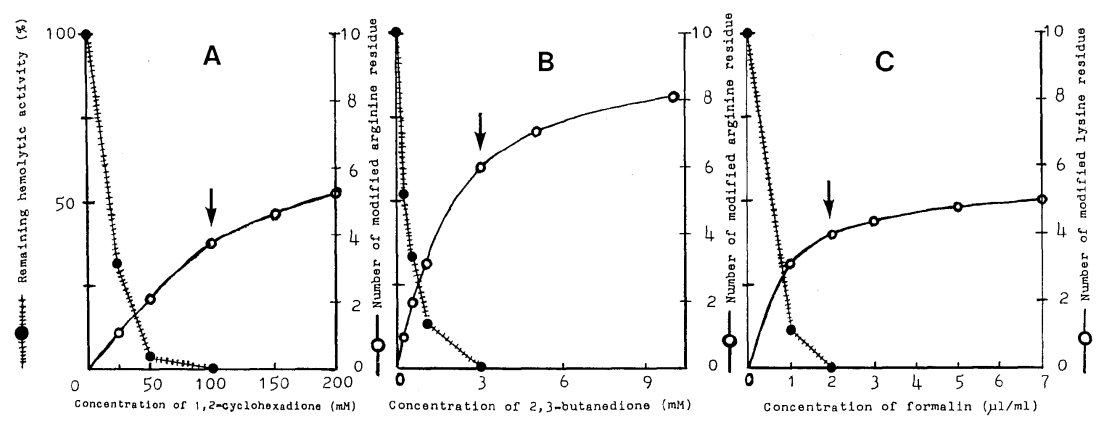

Fig. 1. Decrease in the content of specific amono acid residue and loss of hemolytic activity during modification of Asp-hemolysin by modification with 1,2-cyclohexadione (A) and 2,3-butanedione (B), and by reductive methylation with formalin $(\mathrm{C})$. The reaction conditions of chemical modification were determined as described in the text. After remove of excess chemical reagents by gel filtration the remaining hemolytic activity was assayed under standard conditions; Two milliters of $2 \%$ human erythrocyte suspension were added to tubes containing $3 \mathrm{ml}$ of the sample solution, and the mixture solution was incubated for $30 \mathrm{~min}$ at $21 \pm 2^{\circ} \mathrm{C}$. After the incubation, the mixture was centrifuged for $5 \mathrm{~min}$ at $1,500 \mathrm{rpm}$. Hemolysis was monitored by absorbancy at $541 \mathrm{~nm}$.

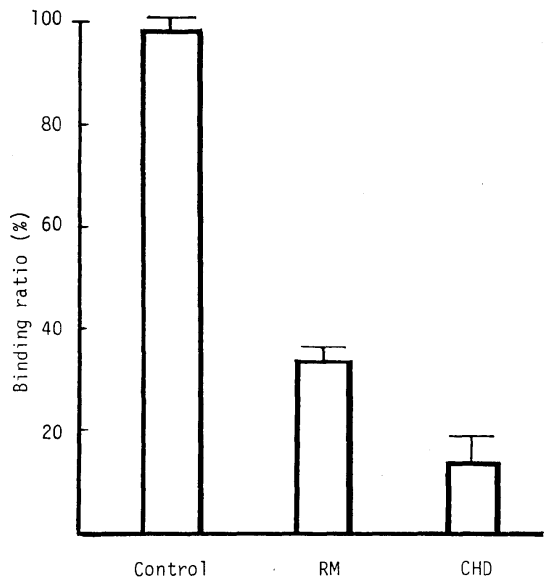

Fig. 2. Rates of binding of chemically modified Asp-hemolysin to human erythrocyte ghost membranes. The binding rates were obtained by the single radial immunodiffusion technique of Mancini et $\mathrm{al}^{15}$. Each bar indicates the mean \pm S.E. $(n=5)$. Binding ratio (\%) was expressed as described in the text.

modified with BDO, and the BDO-modified toxin almost completely lost its capacity to bind to antiAsp-hemolysin serum. Therefore, it was impossible to determine the binding rate for the toxin modified with BDO (data not shown).

\section{Amino acid composition of modified toxin}

The amino acid compositions of the native toxin
Table 1. Amino acid composition of chemically modified Asp-hemolysin

\begin{tabular}{|c|c|c|c|c|}
\hline \multirow{3}{*}{ Amino acid } & \multicolumn{4}{|c|}{$\begin{array}{l}\text { Number }{ }^{a)} \text { of amino acid } \\
\text { residue per mole of }\end{array}$} \\
\hline & \multirow{2}{*}{$\begin{array}{l}\text { Asp-hemolysin } \\
\text { (Control) }\end{array}$} & \multicolumn{3}{|c|}{ Modified Asp-hemolysin } \\
\hline & & CHD & $\mathrm{BDO}$ & $\mathrm{RM}$ \\
\hline Lys $^{\text {b) }}$ & 21 & 20.5 & 21.4 & 16.8 \\
\hline $\mathrm{His}^{\mathrm{b})}$ & 3 & 3.8 & 3.0 & 2.7 \\
\hline $\operatorname{Arg}^{\mathrm{b})}$ & 9 & 5.3 & 3.0 & 9.2 \\
\hline$A s p^{b)}$ & 36 & 36.0 & 36.3 & 36.0 \\
\hline $\mathrm{Thr}^{\mathrm{c})}$ & 18 & 17.2 & 17.8 & 18.2 \\
\hline $\operatorname{Ser}^{c)}$ & 22 & 21.0 & 21.0 & 21.0 \\
\hline $\mathrm{Glu}^{\mathrm{b})}$ & 18 & 18.0 & 18.4 & 17.6 \\
\hline $\operatorname{Pro}^{\mathrm{b})}$ & 6 & 6.3 & 6.0 & 6.3 \\
\hline $\mathrm{Gly}^{\mathrm{b})}$ & 30 & 29.7 & 30.0 & 29.0 \\
\hline $\mathrm{Ala}^{\mathrm{b})}$ & 14 & 13.8 & 14.2 & 14.0 \\
\hline Half-Cys ${ }^{b)}$ & 3 & 3.2 & 3.1 & 3.4 \\
\hline $\mathrm{Val}^{\mathrm{d})}$ & 20 & 19.9 & 20.1 & 20.4 \\
\hline Met $^{\text {b) }}$ & 1 & 0.9 & 1.0 & 1.0 \\
\hline $\mathrm{Ile}^{\mathrm{b})}$ & 11 & 10.7 & 11.1 & 11.1 \\
\hline $\mathrm{Leu}^{\mathrm{b})}$ & 8 & 7.7 & 8.0 & 8.0 \\
\hline Tyr ${ }^{b)}$ & 8 & 7.8 & 5.2 & 8.1 \\
\hline $\mathrm{Phe}^{\mathrm{b})}$ & 8 & 8.3 & 8.2 & 8.1 \\
\hline $\operatorname{Trp}^{\mathrm{e})}$ & 4 & 3.8 & 3.9 & 4.0 \\
\hline
\end{tabular}

Amino acid content was analyzed at the point indicated by each arrow in Fig. 1.
a) Based on a molecular weight of 30,000 .
b) Average value from 24 and $48 \mathrm{hr}$ hydrolysis.
c) Extrapolated to zero time.
d) Analyzed as cysteic acid in the formic acid- oxidized Asp-hemolysin.
e) Determined from the UV-spectrum. 
and the modified toxin are shown in Table 1 . The significant changes occurred only in the arginine, lysine and tyrosine residues. The other amino acid residues remained essentially unchanged during the chemical modification with $\mathrm{CHD}, \mathrm{BDO}$ or by RM. In modification of the toxin with BDO, changes were detected in two amino acid residures, arginine and tyrosine. This result is not incompatible with our previous result obtained by chemical modification of the toxin with glyoxal ${ }^{6}$.

In previous papers ${ }^{6,7)}$, we reported individually the existence of binding and hemolytic active sites in Asp-hemolysin molecule using modification reagents. The present data proved simultaneously that Asp-hemolysin contain shemolytic active and binding sites based on findings by using chemical modification with CHD and RM. Further study of the hemolytic mechanism this toxin is needed to elucidate the role of the specific amino acid residues.

We are grateful to Miss Y. Hoshi for her technical assistance.

\section{References}

1) Sakaguchi, O., Yokota, K. and Kamaguchi, A.: Studies on toxin of Aspergillus fumigatus VIII. Biological properties of Asp-hemolysin. Jpn. J. Bacteriol. 32: 821-828, 1977. (in Japanese).

2) Yokota, K., Shimada, H., Kamaguchi, A. and Sakaguchi, O.: Studies on Toxin of Aspergillus fumigatus VII. Purificaiton and some properties of hemolytic toxin (Asp-hemolysin) from culture filtrates and mycelia. Microbiol. Immunol. 21: 11-22, 1977.

3) Ebina, K., Yokota, K. and Sakaguchi, O.: studies on toxin of Aspergillus fumigatus XIV. Relationship between Asp-hemolysin and experiemntal infection for mice. Jpn. J. Med. Mycol. 23: 246—252, 1982 (in Japanese).

4) Ebina, K., Yokota, K. and Sakaguchi, O.: Studies on toxin of Aspergillus fumigatus XVI. Biological properties of Asp-hemolysin as a parasite factor. Jpn. J. Med. Mycol. 24: 245-252, 1983. (in Japanese)

5) Yokota, K., Kamaguchi, A. and Sakaguchi, O.:
Studies on toxin of Aspergillus fumigatus XVIII. Photooxidation of Asp-hemolysin in the presence of various dyes and its relation to the site of hemolytic activity. Microbiol. Immunol. 28: 385-391, 1984.

6) Yokota, K., Ichinowatari, S. and Ebina K.: Studies on toxin of Aspergillus fumigatus XX. Chemical modification of Asp-hemolysin. Jpn. J. Med. Mycol. 25: 332-339, 1984. (in Japanese).

7) Yokota, K., Ichinowatari, S., Ebina, K. and Wakabayashi, N.: Studies on toxin of Aspergillus fumigatus XXI. Site of binding of Asp-hemolysin to erythrocytes and mechanism of inhibition of hemolysis. Jpn. J. Med. Mycol. 26: 70-73, 1985.

8) Ebina, K., Ichinowatari, S. and Yokota, K.: Studies on toxin of Aspergillus fumigatus XXII. Fashion of binding of Asp-hemolysin to human erthrocytes and Asp-hemolysin-binding proteins of erythrocyte membranes. Microbiol. Immunol. 29: 91-101, 1985.

9) Ebina, K., Ichinowatari, S., Wakabayashi, N., Fukuchi, Y. and Yokota, K.: Microscopical investigation of binding fashion of Asp-hemolysin to Chicken Erythrocyte. Tohoku Yakka Daigaku Kenkyu Nemop. 31: 181-187, 1984. (in Japanese).

10) Patthy, L. and Smith, E.L.: Reversible modification of arginine residues. Application to sequence studies by restriction of tryptic hydrolysis to lysine residues. J. Biol. Chem. 250: 557-564, 1975.

11) Riordan, J.: Functional arginyl residues in carboxypeptidase A. Modification with butandione. Biochemistry. 12: 3915-3923, 1973.

12) Patthy, L. and Smith, E.L.: Identification of functional arginine residues in ribonuclease $\mathrm{A}$ and lysozyme. J. Biol. Chem. 250: 565-569, 1975.

13) Riordan, J.F., McQelvany, K.D. and Borders, Jr. C.L.: Arginyl residues. Anion recognition sites in enzymes. Science. 195: 884-886, 1977.

14) Weisgraber, K.H., Innerarity, T.L. and Mahley, R.W.: Role of lysine residues of plasma lipoproteins in high affinity binding to cell surface receptors on human fiblasts. J. Biol. Chem. 253: 9053-9062, 1978.

15) Mancini, G., Carbonara, A.O. and Heremans, J.F.: Immunochemical quantitation of antigens by single radial immunodiffusion. Immunochemistry. 2: 235-254, 1965. 